\title{
Polypropylene/Polyamide 6 In Situ Composite ${ }^{\dagger}$
}

\author{
Xuedong LI, Mingcai ChEn, ${ }^{\dagger \dagger}$ Yuhui HuANG, \\ and Guangmin CoNG \\ Guangzhou Institute of Chemistry, Academia Sinica, Guangzhou, 510650, People's Republic of China
}

(Received February 24, 1997)

\begin{abstract}
The in situ composite consisting of polypropylene (PP) and polyamide 6 (PA6) was obtained with extrusion method in a single screw extruder. It was found that PA6 being the dispersed phase could fibrillated in PP matrix and fibrillation occurred in the channel of the extruder. The notched impact strength increased with the increasing content of PA6 while the tensile strength decrease. The average diameter of the fibrils changed hardly with the changing content of PA6 under the investigated condition. Increasing the draw rate and the impact strength and tensile strength increased obviously. When increasing the rotating speed of screw the dimension of the fibrils also became finer. The mechanical properties decreased with the increasing processing temperature and the average diameter of fibrils increased.

KEY WORDS In Situ Fibrillation Composite / Polypropylene / Polyamide 6 / Thermoplastic / Processing Condition /
\end{abstract}

When a suspension of fluid droplets is subjected to flow, it tend to be deformed and oriented along the flow direction. For two incompatible polymers when the effect of viscous force is larger than that of the interfacial tension, the dispersed phase in flowing blend can form ellipsoids, rods, or fibrils under different viscosity ratio of two components. ${ }^{1}$ The well-known example is the system of liquid crystalline polymer (LCP) and thermoplastic where the dispersed phase is LCP with rigid molecular chain. Many papers had reported the formation of LCP/polymer in situ composites, ${ }^{2}$ and their mechanical properties, rheological property, and so on had been discussed in these papers. ${ }^{3,4}$ For two flexible thermoplastics the dispersed phase can form fibrils in matrix although these fibrils will relax and retract easily because of its flexibility of molecular chain. If the melting temperature of dispersed-phase-formed fibrils is higher than that of the matrix and the composite is molded below the $T_{\mathrm{m}}$ of fibrils, in situ composite with the fibrils is obtained.

To generate the fibrillar morphology three major methods have been used: fiber spinning, extrusion, and injection molding. It has been found that fiber spinning is particularly advantageous because the elongational force field in the spinning process is more effective for producing the fibrillar morphology than the shear force field. Polypropylene (PP)/polyamide 6 (PA6) in situ composite obtained with spinning process had been studied in some papers. ${ }^{5,6}$ Under spinning condition both PP and PA6 could form fibers in the composite. It had not been reported that PP/PA6 in situ composite was obtained under ordinary extrusion processing condition. In the present study, PP/PA6 in situ composite was obtained with a single screw extruder. In this paper it was studied that how the composition and processing conditions influenced the morphology and mechanical properties of the composite.

\section{EXPERIMENTAL}

\section{Materials}

Both PA6 and PP are commercially available. PA6 is the product of Guangzhou Tianyu Petrochemical Corp. Ltd., $M_{\eta}=46000, T_{\mathrm{m}}=220^{\circ} \mathrm{C}$. PP was produced in Russia with melt index of $14.2 \mathrm{~g} / 10 \mathrm{~min}$ and $T_{\mathrm{m}}$ of $160^{\circ} \mathrm{C}$.

\section{Processing}

PA6 was dried at $80^{\circ} \mathrm{C}$ for $6 \mathrm{~h}$, then was extruded with PP in a $\Phi 30-\mathrm{mm}$ single-screw melt extruder according to the following steps:

1. PP and PA6 were blended with different weight ratio as following:

\begin{tabular}{crrrrrrr}
\hline PP & 100 & 95 & 90 & 85 & 80 & 70 & 60 \\
PA6 & 0 & 5 & 10 & 15 & 20 & 30 & 40 \\
\hline
\end{tabular}

The temperature profile of the extruder was $170^{\circ} \mathrm{C} /$ $230^{\circ} \mathrm{C} / 230^{\circ} \mathrm{C} / 225^{\circ} \mathrm{C} / 225^{\circ} \mathrm{C}$, the rotating speed of screw was $80 \mathrm{rpm}$ and the draw rate was $16 \mathrm{~m} \mathrm{~min}^{-1}$.

2. Selected a weight ratio which could provided good mechanical properties then changed the processing conditions, respectively: the draw rate, the rotating speed of screw and the processing temperature, when one of the conditions was changed the other two were constants. Firstly, we adjusted the speed of screw from $30 \mathrm{rpm}$ to $120 \mathrm{rpm}$, when the temperature profile and the draw rate were $170^{\circ} \mathrm{C} / 230^{\circ} \mathrm{C} / 230^{\circ} \mathrm{C} / 225^{\circ} \mathrm{C} / 225^{\circ} \mathrm{C}$ and $30 \mathrm{~m} \mathrm{~min}^{-1}$, respectively. Secondly, when the temperature profile was still $170^{\circ} \mathrm{C} / 230^{\circ} \mathrm{C} / 230^{\circ} \mathrm{C} / 225^{\circ} \mathrm{C} / 225^{\circ} \mathrm{C}$ and the screw speed was fixed as $80 \mathrm{rpm}$, the rate varied from $6 \mathrm{~m} \mathrm{~min}^{-1}$ to $30 \mathrm{~m} \mathrm{~min}^{-1}$. Finally, the screw speed and the draw rate were set as $120 \mathrm{rpm}$ and $30 \mathrm{~m} \mathrm{~min}^{-1}$, respectively, and the temperature of the second and third stage of screw varied from $230^{\circ} \mathrm{C}$ to $290^{\circ} \mathrm{C}$ while the temperature of the other part of screw did not change.

The extrudate were quenched in cool water then were

\footnotetext{
+ Supported by the National Science Foundation of Guangdong Province.

${ }^{\dagger+}$ Corresponding author.
} 
chopped into granulates. The blend was rolled on a twin-roller milling machine at $165-170^{\circ} \mathrm{C}$ then pressed into sheets by compression molding with a planet vulcanizing machine at $180^{\circ} \mathrm{C}$. The mechanical testing samples were prepared from these sheets.

\section{Testing and Characterization}

Mechanical Testing. Tensile testing and notched impact testing were carried out with a tensile tester (product of Guangzhou Materials Testing Machine Factory) and WPM charpy impact tester (made in Germany) according to GB1040-79 (Chinese standard), respectively. Tensile test was run at a crosshead speed of $25 \mathrm{~mm} \mathrm{~min}^{-1}$.

Scanning Electron Microscopy Observation. The extrudates were extracted with xylene in order to dissolve PP matrix, the remnant were gold-sputtered and observed with Hitachi S-430 SEM, the accelerating voltage was $15 \mathrm{kV}$.

\section{RESULTS AND DISCUSSION}

\section{Fibrillation of PA6}

When PA6 and PP were extruded with extruder, the extruder was turned off and the screw was taken out, that the melt adhering to the screw were quenched in the cool water, then the samples on the second and third stage of the screw were obtained, the morphology of PA6 on the two stages was shown in Figure 1.

It was obviously that PA6 fibrillated in the extruder's channel, it indicated that the shear force field was enough for the fibrillation of PA6.

\section{Influence of Composition}

When PP/PA6 were extruded a plenty of fibrils dispersed in PP formed under the processing condition. In general, the fibrils' diameter increase with the increase of PA6 content. But it was found that average diameter of fibrils didn't increase with the increase of PA6 content while the fibrils' numbr became greater. Figure 2 is the SEM micrographs of composites containing different content of PA6 after PP had been extracted completely with xylene. It is considered that the increase in diameter needs the collision, coalescence of dispersed droplets.
However in the present investigated composition scale although the content of PA6 was increased, the PA6 droplets had enough space to flow and deform under the investigated processing condition. The probability of collision was small, the fibrils' collision between droplets was small. Therefore their number increased but the diameters didn't.

Figure 3 shows the relationship between the content of PA6 and tensile strength, the tensile strength of composites would decrease with the increase of PA6's content. It is reasonable for the decrease in tensile strength because the interfacial adhesion of PP and PA6 is very weak. In slow stress field (tensile) the interface acted as stress concentration point and would form voids in PP matrix, so the strength will decrease with the increasing in the number of fibrils. Figure 4 is the scanning electron micrographs of tensile fracture surface of PP/PA6 in situ composite. It shows clearly that the number of fibrils on the fracture surface of tensile sample containing higher content of PA6 is greater than that containing lower content of PA6.

Figure 5 shows the relationship between the concentration of PA6 and the notched impact strength. When the concentration of PA6 increased, the impact strength also increased. It can be understood easily that the impact strength of incompatible two-phase composite which has latex morphology will be larger than that of the matrix. In the fibrils-dispersing blend these fibrils can undertake stress and break to disperse impact energy. The more the number of fibrils, the more the impact energy dispersed by fibrils. This is why the notched impact strength increases with the increase of PA6's content. Figure 6 shows that on the impact fracture surface the number of fibrils increases with content of PA6.

\section{Influence of Processing Condition}

Rotating Speed of Screw. When studying the shear flow of the emulsions, it was found that the deformation $D$ was regulated by the following factors according to eq 1 as followed,

$$
D=\left(G b \eta_{0} / \gamma\right)(19 \lambda+16) /(16 \lambda+16)
$$

where $D=(L-B) /(L+B), L, B$ are the dimensions of

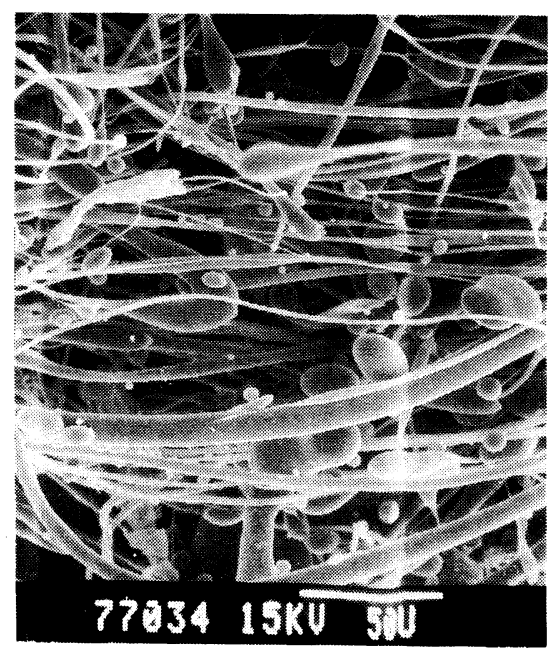

(a)

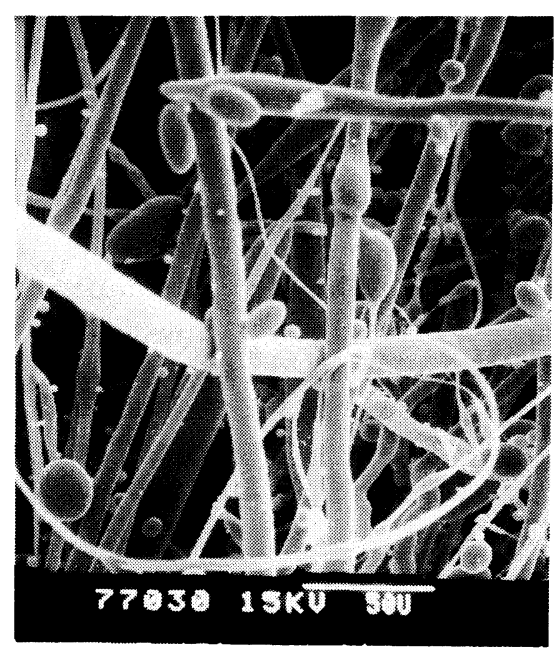

(b)

Figure 1. Morphology of PA6 in the different zones of screw channel. (a) compression zone; (b) metering zone. 


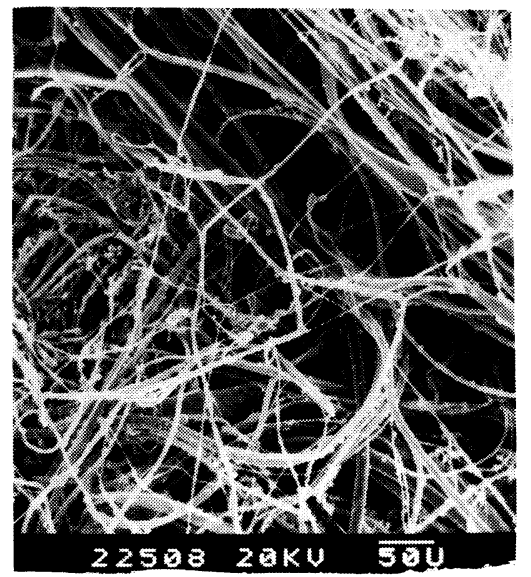

(a)

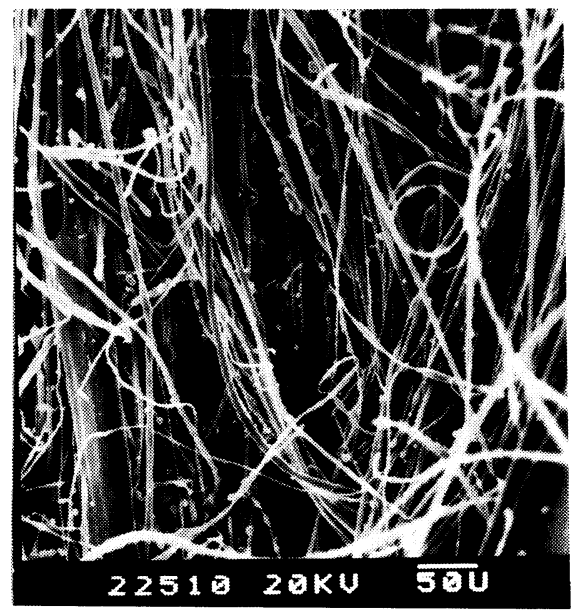

(b)

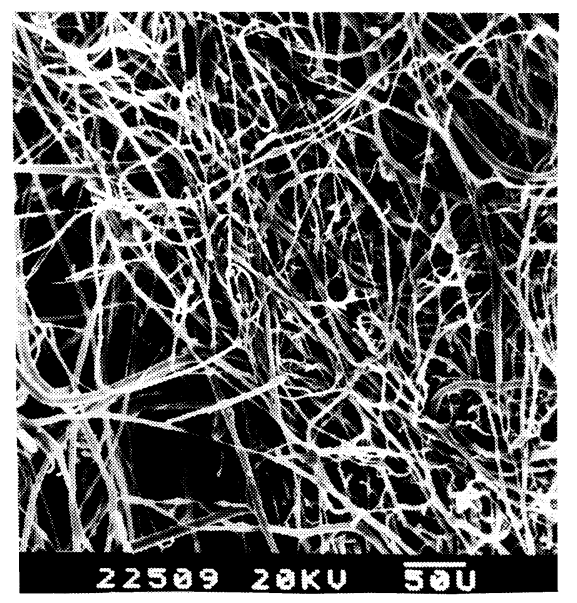

(c)

Figure 2. SEM micrographs of PA6 fibrils in PP/PA6 in situ composite after PP have been extracted completely. (a) 95/5PP/PA6; (b) 70/30PP/PA6; (c) $60 / 40 \mathrm{PP} / \mathrm{PA} 6$.

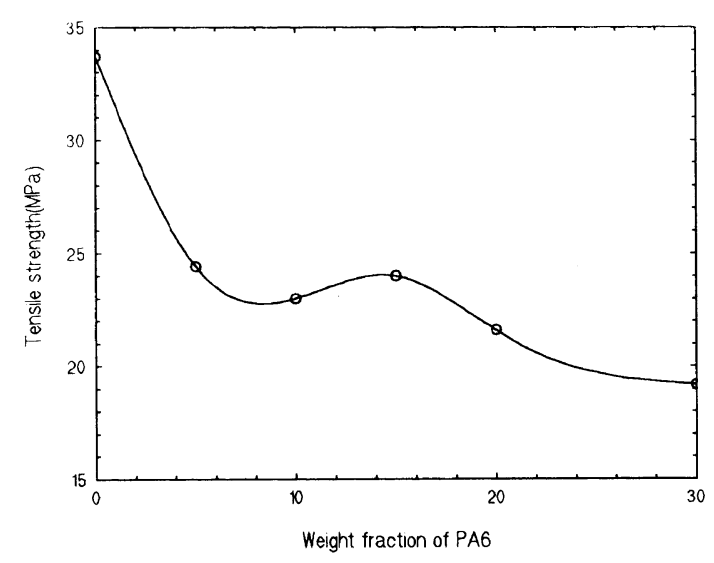

Figure 3. The relationship between the tensile strength and the content of PA6.

major axis and minor axis of deformed drop, respectively, $G$, the shear rate of the shear flow field; $b$, the radius of droplet before it deformed; $\eta_{0}$, the viscosity of the medium; $\gamma$, the interfacial tension.

In shear flow field, $D$ was determined by $G, \eta, b, \gamma$, and $\lambda$, when $G$ changes $\eta, b$ and $\lambda$ will change with it, as a result $D$ will change.
It should be pointed out that eq 1 is suitable for the flow of the emulsions in which the deformation is small. When the deformation of the dispersed phase is very large, such as the deformation of the dispersed droplets in polymer blends, this equation cannot be used to calculated the amount of deformation quantatively, but it still shows the qualitative relationship between the deformaton and the influencing factors.

In extrusion process the melt in the screw channel is subjected to the shear force provided by the screw, in a single screw extruder the shear rate can be calculated using eq 2 ,

$$
G=\pi d N / H
$$

where $d$ is the diameter of screw, $N$ is the rotating speed of screw, $H$ is the depth of the screw trough, in the present study $d / H \approx 6$.

The rotating speed is an important factor that influences the shear rate $G$ and $\eta_{0}, \eta_{1}, \lambda$. It affects the deformation $D$, the dimension of fibril changes.

In the present study the draw rate was set at 30 $\mathrm{m} \mathrm{min}^{-1}$, the temperature profile of the extruder was $170^{\circ} \mathrm{C} / 230^{\circ} \mathrm{C} / 230^{\circ} \mathrm{C} / 225^{\circ} \mathrm{C} / 225^{\circ} \mathrm{C}$, the rotating speed of screw was the following value respectively: $30,50,70$, 


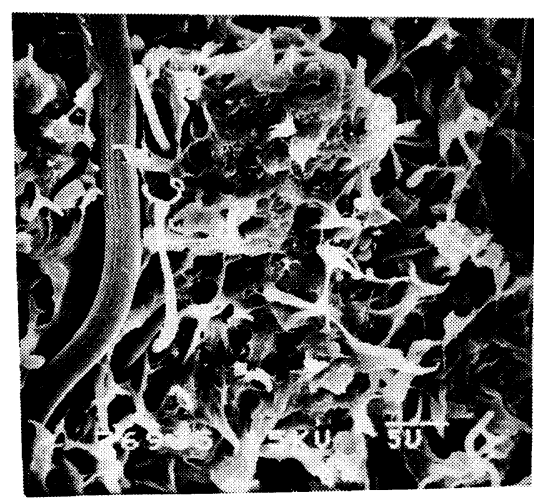

(a)

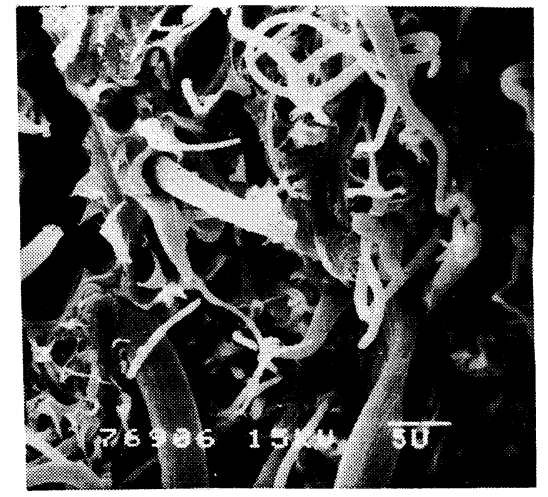

(b)

Figure 4. SEM micrographs of the tensile fracture surface of PP/PA6 composite. (a) 90/10PP/PA6; (b) 70/30PP/PA6.

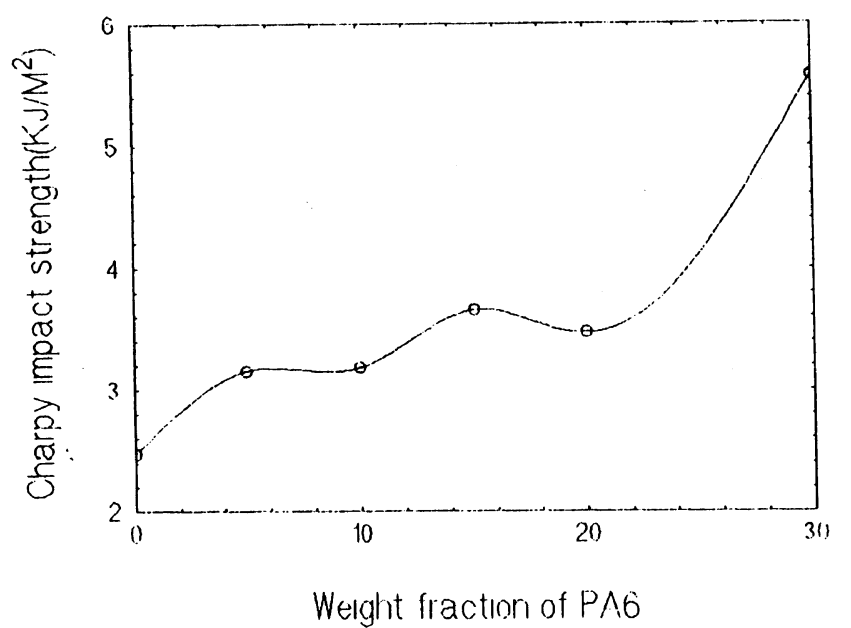

Figure 5. The relationship between the impact strength and the content of PA6.

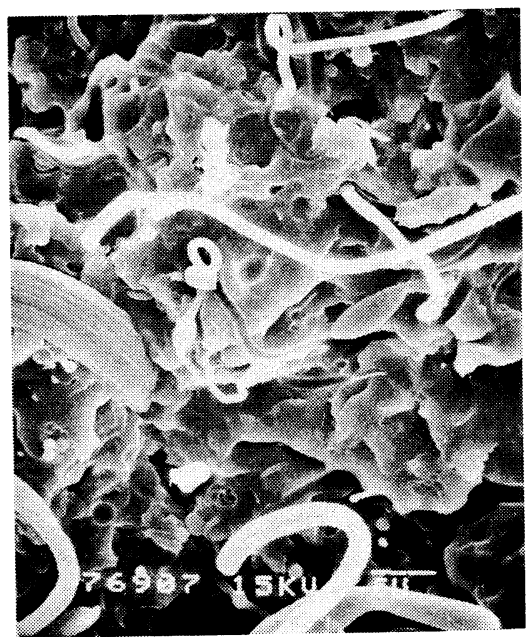

(a)

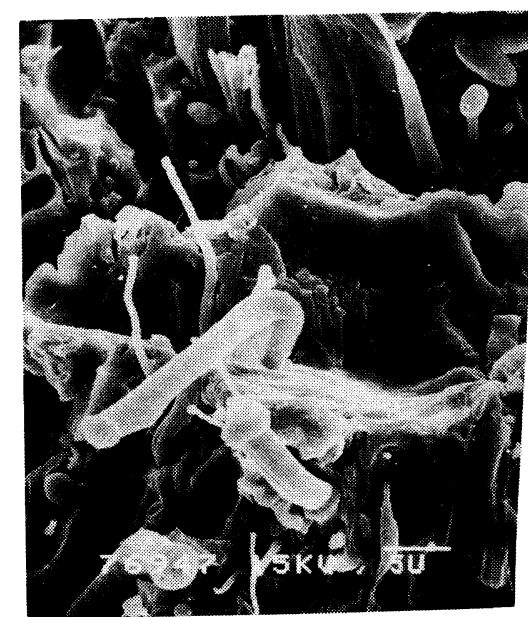

(b)

Figure 6. SEM micrographs of the impact fracture surface. (a) 90/10PP/PA6; (b) 70/30PP/PA6.

90, and 120 rpm. SEM micrographs of PA6 (Figure 7) shows that the average diameter of PA6 fibrils decreased with the increase in the rotating speed of screw. With the increasing shear rate the deformation $D$ increased, the deformed PA6 phase formed the finer fibrils. It was also found that when the rotating speed of screw was very high, the number of small spherical droplets increased. The reason was that the droplets were too small to deform and the probability of the coalescence between the droplets decreased.

The mechanical properties of the composites processed with different rotating speed of screw were shown in 


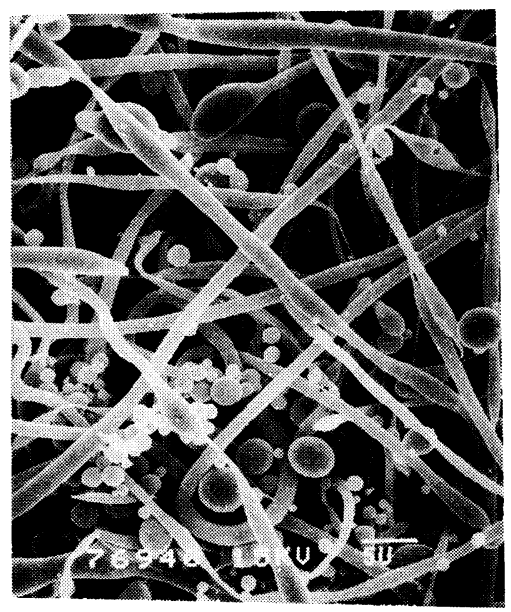

(a)

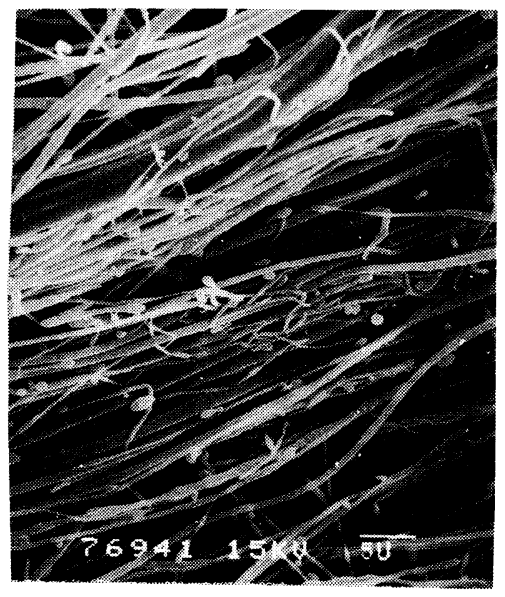

(b)

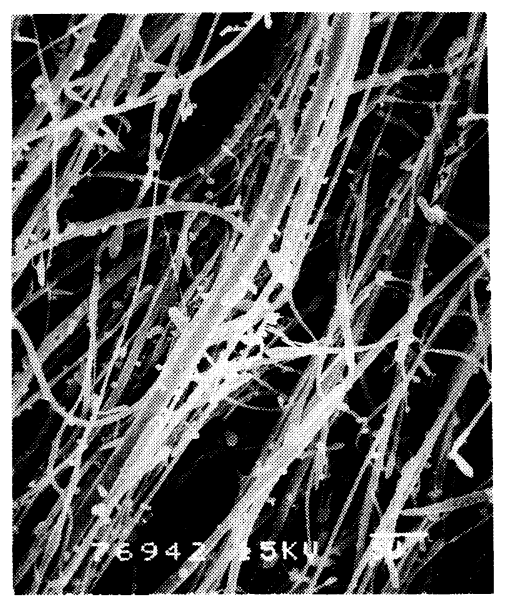

(c)

Figure 7. SEM micrographs of PA6 in PP/PA6 composite when changing the rotating speed of the screw. (a) $n=30 \mathrm{rpm}\left(G \approx 600 \mathrm{~s}^{-1}\right), d_{\mathrm{a}}=1.49 \mu \mathrm{m}$; (b) $n=70 \mathrm{rpm}\left(G \approx 1400 \mathrm{~s}^{-1}\right), d_{\mathrm{a}}=0.83 \mu \mathrm{m}$; (c) $n=120 \mathrm{rpm}\left(G \approx 2400 \mathrm{~s}^{-1}\right), d_{\mathrm{a}}=0.51 \mu \mathrm{m}\left(n\right.$ denotes the rotating speed of screw, $d_{\mathrm{a}}$ denotes the average diameter of fibrils).

Table I. The mechanical properties of PP/PA6 in situ composites processed with different rotating speed of screw

\begin{tabular}{ccc}
\hline Rotating speed & Charpy impact strength & Tensile strength \\
\cline { 1 - 1 } rpm & $\mathrm{kJ} \mathrm{mol}^{-2}$ & $\mathrm{MPa}$ \\
\hline 30 & 3.61 & 24.5 \\
50 & 5.29 & 23.3 \\
70 & 6.26 & 23.1 \\
90 & 5.26 & 23.9 \\
120 & 7.10 & 22.4 \\
\hline
\end{tabular}

Table I. It was clear that the tensile strength decreased slightly while the impact strength was improved obviously.

PP and PA6 are incompatible. The number of weak interface was larger with increasing number of fibrils, it resulted that the tensile strength decreased under the tensile condition whose testing rate was very slow and resulted strain was large. But on the other hand, the finer was the fibrils, the stronger was the physical adhesion. It resulted that the fibrils could dispersed stresses, so the tensile strength would be improved. The effect of the two
Table II. The mechanical properties of PP/PA6 in situ composites subjected to different draw rate

\begin{tabular}{|c|c|c|}
\hline Draw rate & Charpy impact strength & Tensile strength \\
\hline $\mathrm{m} \mathrm{min}^{-1}$ & $\mathrm{~kJ} \mathrm{~mol}^{-2}$ & $\mathrm{MPa}$ \\
\hline 6 & 4.44 & 16.4 \\
\hline 12 & 4.80 & 21.6 \\
\hline 18 & 4.94 & 22.8 \\
\hline 24 & 4.68 & 24.7 \\
\hline 30 & 6.10 & 22.6 \\
\hline
\end{tabular}

factors counteracted each other, as a result the tensile strength just changed slightly. When the impact test was carried out, the strain was small and the testing rate was fast, the fibrils could disperse lots of impact energy, the more the number of the fibrils, the higher the impact strength.

Draw Rate. The draw rates varied from $6 \mathrm{~m} \mathrm{~min}^{-1}$ to $30 \mathrm{mmin}^{-1}$ and the step was $6 \mathrm{~m} \mathrm{~min}^{-1}$, the rotating speed of screw and the temperature were set at $80 \mathrm{rpm}$ and $170^{\circ} \mathrm{C} / 230^{\circ} \mathrm{C} / 230^{\circ} \mathrm{C} / 225^{\circ} \mathrm{C} / 225^{\circ} \mathrm{C}$, respectively. Figure 8 was the SEM micrographs of PA6 processed at different draw rate. It was clear that the average 


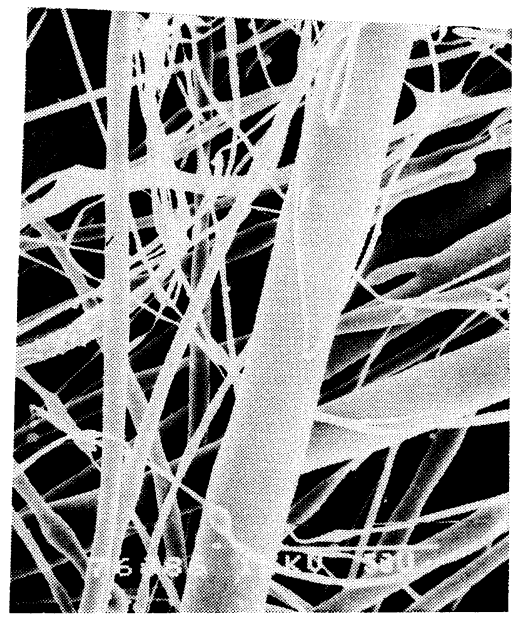

(a)

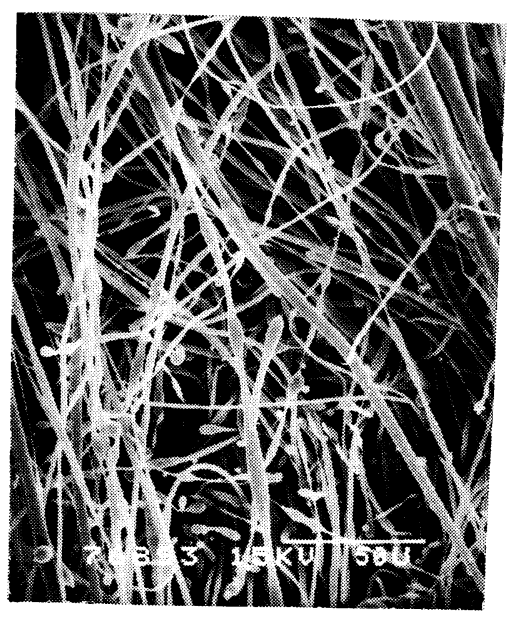

(c)

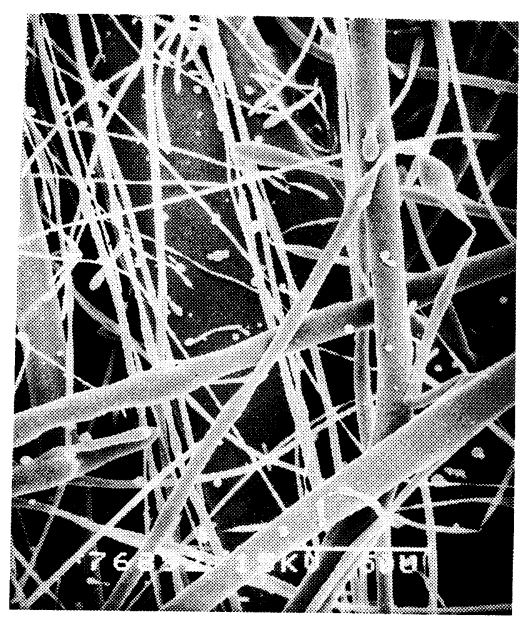

(b)

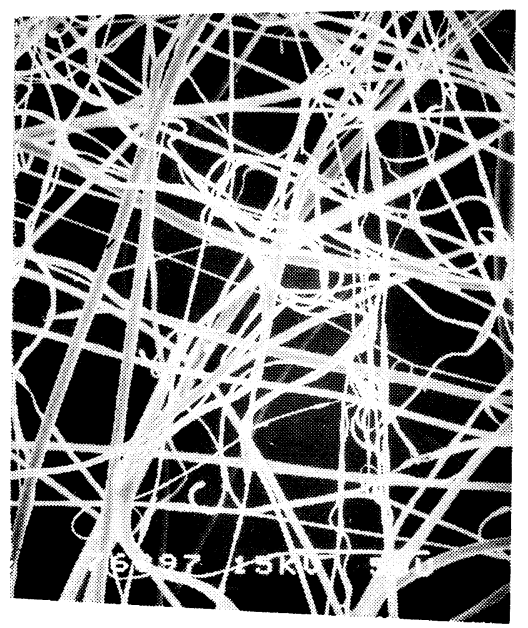

(d)

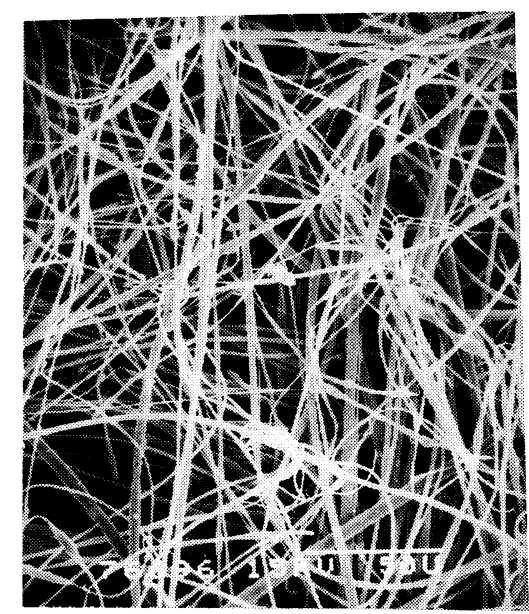

(e)

Figure 8. SEM micrographs of PA6 when changing the draw rate. (a) $D R=6 \mathrm{~m} \mathrm{~min}^{-1}, d_{\mathrm{a}}=9.15 \mu \mathrm{m}$; (b) $D R=12 \mathrm{~m} \mathrm{~min}^{-1}, d_{\mathrm{a}}=5.77 \mu \mathrm{m}$; (c) $D R=18 \mathrm{~m} \mathrm{~min}^{-1}, d_{\mathrm{a}}=2.92 \mu \mathrm{m}$; (d) $D R=24 \mathrm{~m} \mathrm{~min}^{-1}, d_{\mathrm{a}}=2.46 \mu \mathrm{m}$; (e) $D R=30 \mathrm{~m} \mathrm{~min}^{-1}, d_{\mathrm{a}}=2.12 \mu \mathrm{m}$ ( $D R$ denotes the draw rate, $d_{\mathrm{a}}$ denotes the average diameter of fibrils).

diameter of the fibrils decreased when the draw rate increase. The diameter distribution of PA6 fibrils was more narrow. It indicated that the effect of draw was advantage for that the fibrils became finer and longer and for more uniformity of the fibrils' size.
That the mechanical properties of the composite which was processed at different draw rate was listed in Table II. The tensile and impact strength were improved with increasing draw rate. The improvement was related to the change of the morphology. Because the diameter of 


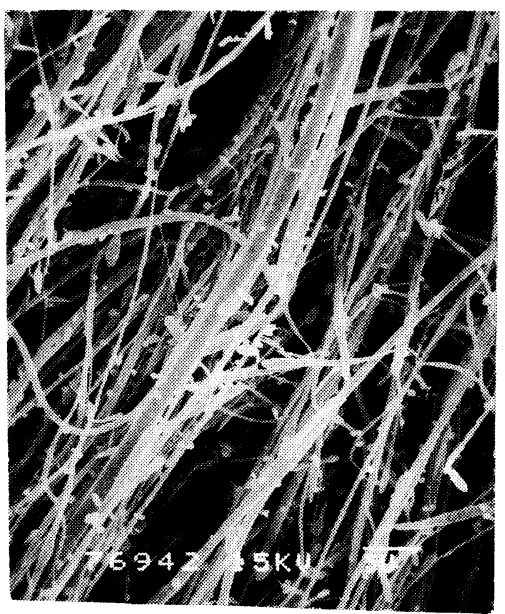

(a)

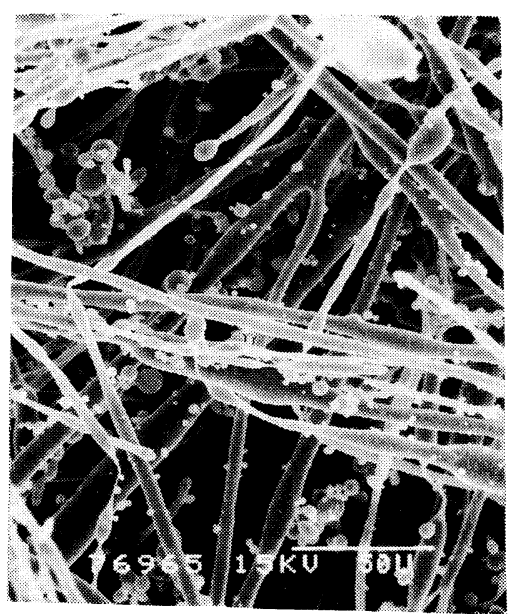

(b)

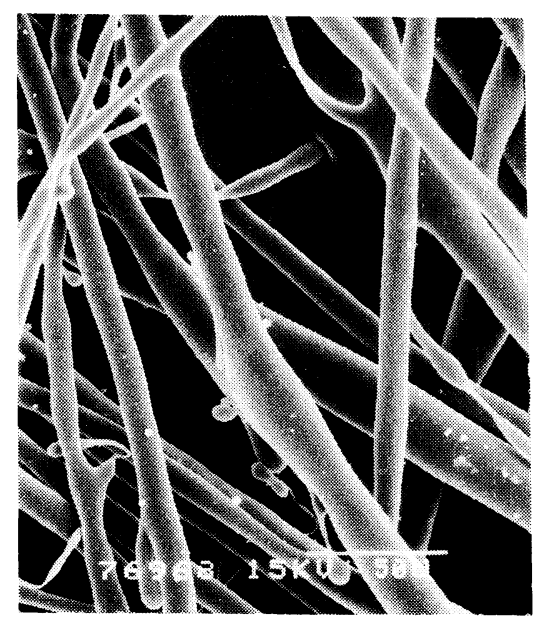

(c)

Figure 9. SEM micrographs of PA6 in PP/PA6 composite processed with different processing temperature. (a) $230^{\circ} \mathrm{C}$; (b) $260^{\circ} \mathrm{C}$; (c) $290^{\circ} \mathrm{C}$.

PA6 fibrils decreased PP matrix and PA6 fibrils tended to adhere tightly. When the draw rate increased, it was advantage for that the interface transferred stress to PA6 fibrils whose strength was high and the load was dispersed uniformly in all parts of the materials. As a result that the strength was improved.

\section{Processing Temperature}

Processing temperature can affect the interfacial tension and the viscosity ratio of the two phases. The morphology of the dispersed phase and the mechanical properties will chang with the change of processing temperature.

The different processing temperatures of the second and third stages were shown as the following:

\begin{tabular}{ccc}
\hline Condition & 2nd stage & 3rd stage \\
\hline$T_{1}\left({ }^{\circ} \mathrm{C}\right)$ & 230 & 230 \\
$T_{2}\left({ }^{\circ} \mathrm{C}\right)$ & 260 & 260 \\
$T_{3}\left({ }^{\circ} \mathrm{C}\right)$ & 290 & 290 \\
\hline
\end{tabular}

When the processing temperature increased, it was found that the average diameter of PA6 fibrils increased (shown in Figure 9). The possible reason was that the Polym. J., Vol. 29, No. 12, 1997
Table III. The mechanical properties of PP/PA6 in situ composites processed at different temperature

\begin{tabular}{|c|c|c|}
\hline \multirow{2}{*}{$\begin{array}{l}\text { Processing } \\
\text { temperature }\end{array}$} & Tensile strength & Charpy impact strength \\
\hline & $\mathrm{MPa}$ & $\mathrm{kJ} \mathrm{mol}^{-1}$ \\
\hline$T_{1}=230^{\circ} \mathrm{C}$ & 22.4 & 7.10 \\
\hline$T_{2}=260^{\circ} \mathrm{C}$ & 22.5 & 5.56 \\
\hline$T_{3}=290^{\circ} \mathrm{C}$ & 22.9 & 4.69 \\
\hline
\end{tabular}

higher the processing temperature, the lower the viscosity of PP which decreased the viscous force on the dispersed phase. As a result the average diameter increased.

The mechanical properties of the composites processed at different temperature were shown in Table III. The impact strength decrease with the increasing processing temperature. While the tensile strength just changed slightly.

\section{CONCLUSIONS}

For two kinds of thermoplastic PP and PA6 the shear flow field is enough for PA6 deforms and fibrillates in PP matrix and form in situ composite. Under the investigated condition the diameter of fibrils hardly 
change with the amount of PA6. When pressed by compression molding at the temperature between the $T_{\mathrm{m}}$ of PP and PA6 the fibrillar morphology can be maintained. The impact strength is improved with the addition of PA6 while the tensile strength decreased.

It is found that the processing conditions involving draw rate, rotating speed of screw and temperature have strong influence on the morphology and the mechanical properties of the composite.

1. Increasing the rotating speed of screw, PA6 fibrils will be finer and the impact strength is improved obviously, while tensile strength only changes slightly.

2. The faster the draw rate, the smaller of the average diameter of PA6 fibrils and the more narrow the dimension distribution, the better the mechanical properties.
3. Increasing the processing temperature, the dimension of fibrils becomes larger and the impact strength decreased.

\section{REFERENCES}

1. H. Van Oene, J. Colloid. Interface Sci., 40, 448 (1972).

2. G. Kiss, Polym. Eng. Sci., 27, 410 (1987).

3. M. T. Heino, P. T. Hietaoja, T. P. Vainio, and J. V. Seppala, J. Appl. Polym. Sci., 51, 259 (1994).

4. O. Roetting and G. Hinrichsen, Adv. Polym. Tech., 13, 57 (1994).

5. B. R. Liang, J. L. White, J. E. Spruiell, and B. C. Goswami, J. Appl. Polym. Sci., 28, 2011 (1983).

6. A. Mehta and A. Isayev, Polym. Eng. Sci., 31, 971 (1991).

7. F. D. Rumschcidt and S. G. Mason, J. Colloid. Interface Sci., 16, 238 (1961). 